\title{
EL PENSAMIENTO POLÍTICO DE BLANCO- WHITE. SUS CONFLICTOS CON LAS CORTES DE CÁDIZ POR LA PUBLICACIÓN DEL NÚMERO 13 DEL PERIÓDICO EL ESPAÑOL
}

Jesús López de Lerma Galán

(Universidad de Sevilla)

jllerma2002@yahoo.es

\section{Resumen:}

La lucha intelectual y política por el reconocimiento legal de la libertad de imprenta en el siglo XIX ha tenido diferentes escenarios y protagonistas. La aprobación del decreto de libertad política de imprenta en 1810, generó el desarrollo de publicaciones en la península como nunca antes se había producido. Sin embargo, las circunstancias políticas de la época obligaron a muchos españoles a exiliarse de su país y crear periódicos en el extranjero en los que poder manifestar sus ideas ante los cambios y transformaciones de su patria. Éste es el caso de la figura de Blanco-White y el periódico El Español, todo un ejemplo que refleja el desarrollo de la prensa en el exilio.

Palabras clave: Cortes, periódico liberal, exilio, libertad de prensa.

\begin{abstract}
:
The intellectual and political fight for the legal recognition of the printing freedom in the nineteenth century has had different stages and protagonists. The approval of the ordinance of freedom printing politics in 1810 generated the development of publications in the peninsula like never before had taken place. However, the political circumstances of the time forced many Spaniards to leave their country and to create newspapers abroad in those that to be able to manifest their ideas before the changes and transformations of their homeland. This is the case of the figure of Blanco-White and the newspaper El Español, an entire exponent that reflects the development of the press in the exile.
\end{abstract}

Keywords: Courts, liberal newspaper, exile, press freedom. 
El pensamiento político de Blanco-White...

\section{INTRODUCCIÓN}

E Español fue un periódico mensual publicado en Londres por Blanco-White desde abril de 1810 a junio de 1814. Sus números llegaban a Cádiz provocando la indignación de serviles y liberales. Esta publicación es un ejemplo de la labor que en el extranjero realizaron muchos periodistas españoles exiliados como Blanco-White, pero para conocer los detalles de este periódico debemos incidir en algunos aspectos biográficos de su creador (Blanco-White, 1973 y 1988; Lloréns, 1979). Su verdadero nombre era José María Blanco Crespo, hijo de padres sevillanos, descendía por línea paterna de una de las familias irlandesas que a principios del XVIII emigraron de su país por motivos religiosos. Estudió en la Universidad Hispalense y a los veinticuatro años se ordenó sacerdote, convirtiéndose en 1801 en capellán magistral de la Real Capilla de San Fernando. A finales de 1805 marchó a Madrid para ser catequista en el Instituto Pestalozziano. Su vida, marcada por una lucha interna y sus dudas religiosas, lo abocan a sucumbir ante la pasión de una mujer, Magdalena Esquiva, con la que tendrá un hijo (Tobajas, 1984: 169-171). La entrada de los franceses en Madrid motiva su huida en 1808 hasta llegar a Sevilla donde su nombre pasará a relacionarse con la publicación El Semanario Patriótico, un periódico impulsado por el liberal Quintana, que surgió brevemente en Madrid ese mismo año para luchar contra el invasor napoleónico. La llegada de las tropas acabó con esta publicación que sacó sólo 13 números, pero será en Sevilla donde volverá a surgir quedando en 1809 bajo la dirección de Isidoro Antillón y BlancoWhite. Esta nueva etapa duró sólo tres meses y medio, y su ruptura vino motivada por el enfrentamiento entre poder y prensa. Quintana quiere que la publicación esté al servicio de la Junta Central, que coordina la guerra contra el invasor; mientras que Blanco-White adopta una postura más crítica frente al poder y piensa que la Junta Central debe hacer reformas más radicales (Valls, 1988: 66-70). Blanco huye a Cádiz escapando de nuevo de los franceses, decide romper con su vida de sacerdote, ser fiel a sus principios e ideas y escapar de España rumbo a Inglaterra en 1810, donde se convirtió en el editor de El Español (Tobajas, 1984: 171-172).

La influencia anglófila de Blanco-White y su admiración por las instituciones, provenía de su amistad con Lord Holland, un destacado miembro del partido whig, que pretendió contrarrestar el influjo de las ideas francesas que predominaban entre los liberales de las Cortes de Cádiz. Holland defendía los trazos esenciales del constitucionalismo ingles caracterizado por el espíritu moderado y conciliador entre el pasado y el presente, rechazo de las concepciones abstractas, y una participación decisiva de la Corona en los asuntos estatales. Además de este intelectual inglés, Blanco-White tuvo afinidad con Jovellanos pues ambos deseaban unas Cortes en las que nobleza y clero estuvieran representados. Políticos como Quintana, también fueron foco de influencia para el liberal sevillano, al igual que Ángel de la Vega Infanzón, uno de los diputados que el reino de Asturias había enviado a Inglaterra tras la invasión francesa y al que Blanco tuvo ocasión de conocer en Londres (Varela Suanzes, 1993: 103-106). Blanco fue un hombre comprometido con los problemas de su época y, desde su refugio londinense, desarrolló una importante actividad literaria con trabajos como Letters from Spain, una obra escrita en inglés bajo el seudónimo de Leucadio Doblado, publicada por primera vez en Londres en 1822, y que es, en opinión de Juan Goytisolo, el documento más vivo, y profundo para juzgar a España y a los españoles del siglo XIX (Goytisolo, 1999: 43). Letters from Spain, traducido al castellano por Antonio Garnica bajo el título Cartas de España, encierra una fuerte 
crítica sobre la religiosidad y la estructura social española, al mismo tiempo que muestran un inequívoco amor del autor hacia su patria de origen. En sus páginas se describen costumbres de la sociedad española como la Semana Santa de Sevilla, las tradiciones de la sociedad andaluza y la vida de la corte en Madrid, narrando acontecimientos destacados de aquella época como el motín de Aranjuez y el Dos de Mayo (Garnica, 1973).

El Españo/ tenía una periodicidad mensual y cada número constaba de 90 páginas en cuarto. Blanco utilizó sus recursos para hacer una defensa de la causa de España y la alianza con Inglaterra frente a Napoleón, luchó por los intereses americanos y criticó la política de los gobiernos de la resistencia española, especialmente la labor legislativa de las Cortes de Cádiz. Sus escritos indignaban a las Cortes, se le calificó como antiespañol y antipatriota y fue odiado por muchos de los diputados que en otro tiempo fueron sus amigos (Lloréns, 1989: 34). En el primer número de esta publicación su autor define el alzamiento peninsular contra los invasores franceses como una explosión de dignidad y de libertad (Seco Serrano, 1983: 266). Esta publicación arremetió contra la Constitución de Cádiz y las propias Cortes que la elaboraron, acusando a éstas de acaparar todo el poder del maltrecho Estado, lo que implicaba un riesgo para la libertad (Varela Suanzes, 1993: 106-1067 Sánchez García, 2004: 226).

La trascendencia de El Español (1810-1814) se debe al papel valiente y pionero de oposición crítica a la política del Gobierno en España. También supuso un excelente periódico informativo sobre los sucesos peninsulares, americanos y de la política de Westminster, incomparable a cualquiera de los editados por entonces en Cádiz. Hay que añadir que esta publicación ejercitó una gran labor cultural que sirvió para que los españoles pudieran conocer otras ideas políticas (Moreno Alonso, 1998: 159-160). El primer número de El Español está fechado en abril de 1810, apareció en Londres, y en esta edición de inicio se incluyó un amplio artículo bajo el título Reflexiones generales sobre la revolución española. En dicho texto, que trata sobre la historia de España, el autor ataca a las Juntas provinciales y Central, y plantea la necesidad de una revolución. Al día siguiente de la aparición de este número el embajador de España en Londres, Ruiz de Apodaca, escribió al Secretario de Estado en la regencia de Cádiz denunciando que El Español era un periódico subversivo. Se llegó incluso a avisar al Capitán General de Galicia para que evitara que los ejemplares del periódico que llevaba el buque Los Dos Hermanos pudieran repartirse a su llegada a La Coruña. Meses después, en agosto, la Regencia expidió una orden que prohibía la circulación de El Español en las provincias americanas (Tobajas, 1984: 173-174).

Las ideas del editor se dieron a conocer en lo que se denominó como el Prospecto de El Español. En dicho programa se indica que este periódico se publicará una vez al mes, y estará dividido en varias secciones como política, extractos de los papeles extranjeros y otra literaria (Moreno Alonso, 1998: 163). La cuestión americana es tratada por Blanco en el número IV de El Español, de 30 de julio de 1810, en dos artículos "Revolución en Caracas" y "Reflexiones políticas". La indignación de Cádiz aumentó por estos asuntos puesto que Blanco se mostraba muy comprensivo con las posturas de los americanos y no era partidario de una secesión sino de una autonomía e igualdad de derechos entre españoles y americanos. Lo cierto es que la igualdad era un simple ideal que no se hacía realidad pues los virreyes seguían 
El pensamiento político de Blanco-White...

reinando despóticamente, y la libertad de imprenta no se llevaba a la práctica. Para Blanco esta actitud era injusta e impolítica y a través de sus escritos denunció estos hechos e intentó evitar la ruptura. No sólo fueron los errores de los españoles los que desencadenaron la independencia de la América hispana, sino el deseo de las colonias de liberarse del yugo extranjero. El pensamiento de Blanco respecto al problema americano sigue varias etapas, la primera se centra en los acontecimientos y busca cauces de comprensión a través de las Cortes. En esta línea aplaude el decreto de la Junta Central sobre la igualdad de unos y otros, y el rechazo del término colonias para referirse a los virreinatos americanos. Confía en la existencia de un estado ideal en el que españoles y americanos tengan los mismos derechos civiles y libertades. El Español desempeñará un elemento esencial en esta primera etapa pues se convierte con sus artículos en eje de la revolución de ambos hemisferios. La segunda línea de pensamiento de Blanco en su evolución hacia la actitud americanista, pretende dotar de armonía a la revolución española y americana. En esta etapa en la que se desarrolla el decreto de libertad de imprenta, se ve atacado por las Cortes como traidor de los intereses de España y se inicia la guerra civil trasatlántica. La tercera etapa es un análisis del escritor contra el secesionismo iniciado en Caracas. En 1812 al proclamarse la Constitución de Cádiz y organizarse la nueva Regencia, se entra en una cuarta etapa en la que establece la necesidad de un equilibrio basado en las reformas del texto constitucional y en la restauración de la realeza, que sirva para reconciliar ambos hemisferios (Seco Serrano, 1983: 267273).

Blanco-White abrió un camino hacia el liberalismo conservador, fue precursor del bicameralismo y de la monarquía parlamentaria frente a una Asamblea omnipotente erigida en Cádiz. Su periódico muy difundido en América tuvo gran influencia en el público español, de hecho lo utilizó para plantear toda una serie de alternativas a la Constitución de Cádiz, buscaba un punto de conexión entre la España liberal europeizante y la España reaccionaria castiza. En octubre de 1814 el propio BlancoWhite confiesa que a través de la prensa se había propuesto hallar un camino medio entre la mal fraguada democracia de las Cortes y la arbitrariedad del tiempo de CarIos IV (Varela Suanzes, 1993: 114). La intensidad de sus escritos, la fuerza de sus exposiciones y la constante lucha que desde Inglaterra hizo Blanco-White con su periódico El Español, convirtieron a esta publicación en todo un referente de la prensa política del momento. No obstante, muchas fueron las críticas que recibió por parte de los miembros de las Cortes, pues consideraban a dicho periódico un escandaloso panfleto de ideas revolucionarias que lo único que quería era levantar al pueblo. No apreciaron la capacidad de Blanco de adelantarse a su tiempo, de crear instrumentos democráticos que acercaran más al ciudadano el modelo de parlamentarismo al que se debía aspirar.

\section{EL CONFLICTO DEL NÚMERO 13 DEL PERIÓDICO EL ESPAÑOL EN LOS DIA- RIOS DE SESIONES DE LAS CORTES DE CÁDIZ}

Blanco-White fue víctima de la incomprensión de su generación. No obstante debemos referirnos a El Español como un periódico que marcó la etapa 1810-1814, con noticias y artículos de opinión que atacaron las bases de las Cortes de Cádiz. A continuación analizamos los Diarios de Sesiones de las Cortes donde podemos apreciar el odio que la figura de Blanco-White generó, las intrigas políticas que surgieron con motivo de su publicación y las medidas que se tomaron, por parte de los diputados ${ }^{1}$, 
para evitar futuros ataques. Todo un elenco de situaciones que permiten apreciar bien la valoración política y judicial que se hacía de un periódico que estaba mermando muchos de los postulados y reformas de los liberales.

La sesión del día 24 de mayo 1811 empieza con la exaltación pública del diputado Pérez ${ }^{2}$ por un texto inserto en el número 13 del periódico titulado El Español, en el que se incluye una carta que se suponía dirigida por él al director del periódico. La forma de su intervención, con una clara amenaza de iniciar una querella, ponen de manifiesto la preocupación que existía por parte de los políticos al ver mancillado su honor por publicaciones de dudosa legalidad:

Señor, hoy es día de querellas. ¡Ojalá pudiera desvanecer, como lo ha hecho el Sr. Golfin, con un documento auténtico, la imputación personal que se me ha hecho!, pero no estando por ahora en mi mano el presentarlo, será necesario que V. M. me crea sobre mi palabra, ó que me permita salir a sumergirme en el mar, cuyas aguas quizás no bastarán a lavarme de la mancha con que se ha querido denigrarme (Diario de Sesiones de las Cortes Generales y Extraordinarias, núm. 235, p. 1119).

Pérez, en su argumentación, menciona datos históricos sobre el triunfo de los ejércitos españoles, que entendemos referidos a las luchas contra las tropas francesas, pero seguidamente entra a debatir la publicación de El Español. En su exposición comenta que, al llegar hoy a la sesión, le han dado una carta del editor del periódico mencionado que contesta a la que supuestamente escribió. La lectura de la carta en la sesión está salpicada de interrupciones del diputado donde aclara las incorrecciones de fecha y lugar que aprecia el diputado y que sirven para justificar la suplantación. A continuación reproducimos este fragmento, que sirve para ilustrarnos sobre el tono general de su disertación:

Observe V. M. el poco tino con que está escrita la carta. Dice que es del presidente de la diputación americana. Ni la diputación lo tiene ni yo lo he sido sino del Congreso soberano. Sigue: "Isla de león 22 de febrero de 1811". Este día no estaba yo en la isla porque desde el 21 me hallaba en Cádiz y a medio día vine a este salón, donde me vieron muchos examinando, como Presidente de Cortes, si todo estaba arreglado. (Continuó la lectura de la carta, leyó después la respuesta de Blanco, llamando primero la atención de los Sres. Diputados, por lo que interesaba al mismo Congreso. Luego añadió): Sin que sea necesario asegurar mucho a V. M. que ésta es una suplantación, apelo, a lo que siempre se me ha oído en este Congreso, y a

\footnotetext{
${ }^{1}$ En el desarrollo de este artículo se incluirán referencias sobre los diputados que más destacaron en el proceso de aprobación de los primeros decretos sobre libertad de imprenta y en los debates de las Cortes de Cádiz relacionados con la prensa. No obstante, para ampliar la información sobre los políticos de la época, sería conveniente estudiar la obra y trabajos del profesor García León sobre los diputados doceañistas.

2 Antonio Joaquín Pérez Martínez, nació en Puebla de los Ángeles (México) en 1763, fue sacerdote y catedrático de Filosofía, Teología y Sagradas Escrituras, además de diputado representando al virreinato de Nueva España, llegando a ocupar la presidencia de las Cortes en tres ocasiones. Aunque destacó como político por ser uno de los defensores de la abolición de la Inquisición y la libertad de prensa, posteriormente dejó a sus compatriotas, se unió al grupo de los absolutistas y firmó el Manifiesto de los Persas, pidiendo la reforma de la Constitución. En 1815 regresó a México siendo nombrado obispo de la Puebla, falleciendo en 1829.
} 
El pensamiento político de Blanco-White...

lo que está escrito en los diarios, apelo a mis conversaciones más familiares, y a los modos de urbanidad y política, siempre justa, y en mi general y hereditaria, para que cotejado todo junto, se diga si no está en absoluta contradicción con el contenido de esos impresos (Diario de Sesiones de las Cortes Generales y Extraordinarias, núm. 235, p. 1120).

El honor mancillado por una supuesta carta falsa, obliga al diputado Pérez a solicitar la comprobación y cotejo de su escritura al Gobierno de España, y pedir la colaboración del resto de diputados para defender su inocencia. La principal preocupación reside en el hecho de que este impreso está circulando por todos lados con el correspondiente perjuicio que supone para su persona. Este caso refleja la preocupación existente en la sociedad por los escritos falsos, y nos permite barajar el concepto de atentado al honor, que un uso ilícito de la libertad de expresión podía ocasionar. Por ello, desde las Cortes de Cádiz se estaba tomando tanto celo en establecer una legislación concreta que recogiera los posibles abusos que pudieran surgir. Reflejar estos problemas que se producían en el seno de las sesiones de las Cortes de Cádiz, nos muestra cómo la casuística emergente era muy diversa e incluso se adelantaba a los intentos legislativos. Asistimos, por tanto, a un caso en el que la libertad de imprenta se usa de forma irregular, publicando artículos que implican a los diputados de Cortes, en un periódico escrito en el extranjero.

El presidente de la sala garantiza a Pérez la protección por parte de los miembros de las Cortes. El diputado Esteban solicita al Consejo de Regencia que tome las diligencias para hacer venir por parte del Gobierno inglés la carta original que cita el numero 13, y establece que se encuentran ante un caso de injuria, que al ser por escrito es considerado como libelo (escrito que contiene informaciones falsas), y señala que el diputado Pérez no ha tomado ningún interés por América.

El diputado Leiva ${ }^{3}$ confirma que el testimonio de Pérez negando los hechos es apreciable y que sin él creería que la carta ha sido forjada y dirigida por una persona mal intencionada. Plantea si la imprenta está preparada para desafiar la calumnia y contradecir informaciones contrarias a los intereses de América. Hace una exaltación de los ideales liberales al decir que el que envió la carta estaba engañado al pensar que el único recurso de crítica que tiene un diputado en la época de libertad civil, es remitir un escrito al editor de un periódico publicado en un país extranjero. Leiva tiene especial interés en que se cuente con la carta original, y se publique rápidamente el Diario de esta sesión para que pudiera dirigirse a América, con la finalidad de que comprueben las colonias cómo sus intereses están representados y protegidos en las Cortes.

(...) y solo añado que convendría que manifestando $V$. M. el justo concepto que debe tener sobre la falsedad de la carta, se publicase prontamente el Diario de hoy para que se pueda dirigir a la América. Conviene que aquellos hermanos nuestros estén persuadidos de que sus representantes, sin necesidad de ocurrir a los editores de periódicos, representan y pueden representar libremente en este Congreso cuanto crean conveniente a la felicidad de aquella preciosa parte de la Monarquía española (Diario de Sesiones de las Cortes Generales y Extraordinarias, núm. 235, p. 1120).

3 Diputado americano seglar. 
El diputado Dou ${ }^{4}$ confirma que no se deben dar más pruebas de las que se han dado de la calumnia que se ha cometido, y exigírselas al Sr. Pérez sería poner en duda los sentimientos de veracidad y honor que ha manifestado en el Congreso.

Para Argüelles ${ }^{5}$ la participación de los diputados es fundamental porque asistimos a una ofensa al Congreso nacional en la infame y negra intriga que supone la carta". Plantea que el Gobierno inglés examine sus leyes o disposiciones u obstáculos que pudieran surgir en el envío de la carta original y en la reclamación de responsabilidad. Este caso abre un nuevo tipo de conflicto jurídico pues se está planteando una suplantación de un diputado español en una carta escrita en un periódico considerado extranjero. Señala que el periodista y editor que recibe una carta de una persona desconocida y de otro país y la publica sin comprobación alguna, a sabiendas que las declaraciones contenidas en el texto pueden herir la sensibilidad de los afectados y levantar discordias, demuestra muy poca profesionalidad y es una forma de desacreditarse ante la opinión pública.

Que un periodista inserte en su papel una carta que dice haber recibido, es autoridad desconocida por todo un hombre de juicio y sensatez. Otra es la autenticidad que se requiere en documentos que pueden comprometer la reputación de los hombres de bien. Recibir por correo en un país extranjero de una persona desconocida, cuya firma no está comprobada de un modo auténtico, y en la cual se hallan materias de la mayor importancia y trascendencia, tales, en fin, que pueden encender la discordia entre los amigos más unidos y fieles; recibir esta carta, Señor, y publicarla sin reparo en un periódico, manifiesta en su editor cuando menos una facilidad y ligereza capaces de desacreditar a autoridad más respetable; en el impostor una alevosía profundamente perversa, una depravación desconocida entre nosotros. Por fortuna, no está todavía recibido en ninguna sociedad que se pueda destruir la reputación del hombre de bien sin otras pruebas que un libelo ó la delación de un malvado. No se dé enhorabuena al periódico más importante que la que merece, pero no se desatienda V. M. que su autoridad está injuriada en la persona de un digno Diputado (Diario de Sesiones de las Cortes Generales y Extraordinarias, núm. 235, p. 1120).

\footnotetext{
4 Diputado por Cataluña. El jurisconsulto y literato, Ramón Lázaro Dou De Bassols, nació en Barcelona el 11 de febrero de 1742. Elegido diputado a Cortes durante la Guerra de la Independencia mereció, por su saber y patriotismo, presidirlas en la ciudad de Cádiz en 1811, interviniendo eficazmente en cuantas discusiones de importancia se suscitaron, como la abolición del tormento, la libertad de imprenta, la organización por provincias, los planes de Hacienda, etc. En 1813 fue diputado suplente, siendo además diputado del clero de la provincia de Tarragona. Autor de numerosas escritos, su obra principal fue Instituciones de Derecho público general en España con noticias del particular de Cataluña y de las principales reglas de gobierno en cualquier Estado. Valorado por sus discípulos por su tolerancia, saber y bondad, murió en Cervera el 14 de diciembre de 1832.
}

5 El joven abogado asturiano Agustín Argüelles llegó a Cádiz con una experiencia política nada desdeñable. Había nacido en Ribadesella (Asturias) en 1776, estudió leyes en la Universidad de Oviedo y en 1800 fue a Madrid, donde ocupó una plaza en la Secretaría de Interpretación de Lenguas a las órdenes de Moratín. Trabajó como funcionario del Estado durante el reinado de Carlos IV, desempeñó una importante misión en Inglaterra enviado por la Junta de Asturias y trabajó en diversas comisiones en el seno de la Junta Central. Respecto a su actividad política en Cortes destaca por los grandes discursos parlamentarios en el proceso de aprobación de la libertad de imprenta, su trabajo en la redacción del preámbulo y articulado de la Constitución de 1812, y la defensa de la Constitución de 1837. Murió en Madrid en 1844. 
El pensamiento político de Blanco-White...

Argüelles con estas reflexiones, toca uno de los puntos esenciales en el ejercicio de la profesión periodística como es el deber del periodista de valorar la información y verificar sus fuentes. Son conceptos adoptados actualmente, pero podemos comprobar que será en el seno de las Cortes de Cádiz donde se empieza a hablar sobre la responsabilidad del periodista en los contenidos que publica. También se hace mención a las extrañas maniobras marcadas por la perversidad y la alevosía, que podrían responder a los fenómenos actuales de manipulación informativa con objeto de desacreditar a un político.

El diputado Aner ${ }^{6}$ critica al periódico El Español calificándolo de enemigo de su Patria, peor que el mismo Napoleón. Pese a no mencionarlo directamente, en sus palabras subyace el ataque hacia la figura de Blanco-White (editor de esta publicación), a quien califica como pluma sanguinaria y atrevida que ataca indiscriminadamente a generales, personajes o incluso al Gobierno de España. Aner lo califica como desnaturalizado español que, amparado por la imposibilidad de actuación contra él de la justicia española, castiga a la nación con sus insultos, contribuyendo a que la causa liberal perezca. Los valores patrióticos, la exaltación de la Nación como fuente de poder frente al invasor francés y Napoleón, son constantes características del discurso de este diputado, con expresiones como debe ser proscrito de su Patria puesto que tan descaradamente la insulta, o ¿Y a quién insulta? A una Nación la más heroica del mundo. Aner considera que El Español está calumniando a las instituciones, atribuyendo injustificadamente los delitos más feos, y todos aquellos que adolecían los Gobiernos anteriores. Le preocupa que este periódico circule por múltiples lugares, y que en aquéllos en los que se reciba éste y las publicaciones a favor de Napoleón puedan llevarse una opinión equivocada de la realidad social y política de España. Por ello pide que se establezcan contactos con el Gobierno inglés para que intervenga prohibiéndole escribir al autor de El Español, y que sea considerado proscrito de España:

Léanse sus papeles, y se verá que nos calumnia acriminándonos los delitos más feos, y todos aquellos de que adolecían los Gobiernos anteriores. A mí se me daría muy poco que él escribiera cuanto quisiese; pero su papel se extiende mucho, circula por todas partes, y en aquellas donde no reciban más que éste y los de Napoleón, no podrán menos de decir que nuestra Nación esta subyugada y reducida al último extremo, tanto más, cuanto es un español el que escribe. Por tanto, yo pido a V. M. que se declare por siempre proscrito de España el autor de El Español, y que se influya cuanto sea posible con el Gobierno inglés para que le prohíba escribir (Diario de Sesiones de las Cortes Generales y Extraordinarias, núm. 235, p. 1121).

El diputado Del Monte ${ }^{7}$ propone mandar un ejemplar a la Junta territorial de censura para que lo califique. Si lo considera como subversivo, el Gobierno debe impe-

\footnotetext{
6 Felipe Aner De Esteve (1781-1812) perteneció a la Junta de Gobierno del Valle de Arán, y fue el encargado de redactar las instrucciones de la Junta Superior de Cataluña para los diputados en Cortes. Tras su nombramiento como diputado en Cádiz, destacó por su lucha por ganar la guerra y defender a ultranza los cuerpos francos antes que los militares profesionales.

7 Luis Rodríguez Del Monte nació en 1765 en el Pazo de Serantes (El Ferrol, La Coruña). En 1779 ingresa en la Armada, ocupando en 1808 el cargo de Capitán de Fragata. Fue un diputado liberal, llegando a desempeñar las funciones de presidente de las Cortes en alguna ocasión, además de participar en diversas comisiones. Falleció el 27 de febrero de 1813, tras una larga enfermedad.
} 
dir que se introduzca aquí y en las Américas. Considera al editor un infame e indigno español, que desde el primer número de su publicación se ha declarado enemigo descarado de su Patria. Estos comentarios muestran el odio que se estaba generando por parte de los sectores políticos y sociales respecto a la publicación El Español y la persona de su editor Blanco-White.

La intervención de Gallego ${ }^{8}$ va a aportar datos interesantes para analizar el caso planteado. Leyó un papel en el que un español celoso e ilustrado que reside en Londres (Diario de Sesiones de las Cortes Generales y Extraordinarias, núm. 235, p. 1121) opina sobre la publicación El Español. Aunque el Diario de Sesiones de las Cortes de Cádiz no recoge el texto integro de ese escrito se menciona que su autor se queja de las continuas calumnias y viles imposturas con que se denigra en el periódico en cuestión a la Nación española. Gallego aporta algo más, confiesa que ha sido amigo de Blanco aunque se niega a dar detalles de la estrecha relación que los unía. No obstante reconoce que, en las ediciones que han salido de la publicación cuestionada, se califica mal a España y hay un especial empeño en promover la desunión entre España y América con la ruina que todo ello puede suponer:

Confieso que el autor de El Español ha sido amigo mío, mas cualesquiera que sean las relaciones que me han unido con él, y por las cuales deba abstenerme de hablar de su persona, tengo otros motivos muy poderosos para exponer mi juicio, ya que no sobre las miras e intenciones de Blanco, de que prescindo, sobre lo que en limpio aparece del periódico que publica. Considerado imparcialmente cuanto arrojan de sí los números que han salido hasta el día, resulta que en España ni se puede, ni se quiere, ni se sabe hacer nada bueno; y por lo relativo a las Américas, un empeño constante en promover y atizar la desunión de aquellos países de la madre Patria; desunión que si desgraciadamente se verificase, causaría tal vez la ruina de España, y de seguro la de América (Diario de Sesiones de las Cortes Generales y Extraordinarias, núm. 235, p. 1121).

Gallego señala que en el mismo número en el que se calumnia al Sr. Pérez aparece una carta firmada por Juan Sin tierra que delata una serie de improperios contra la conducta del Congreso, con críticas a los diputados en las que se exceptúan los nombres del Sr. Torrero y Gallego. Del Monte propone que el Consejo de Regencia pase a la Junta territorial de Censura un ejemplar del número 13 del periódico escrito en Londres con el titulo de El Español para que lo califique, y los tribunales decidan de conformidad a la legislación vigente respecto al papel como al autor.

\footnotetext{
8 El poeta Juan Nicasio Gallego, otro de los clérigos liberales, era el diputado más relacionado con los grupos combativos fuera de las Cortes que estaban a favor de la prensa libre. Gallego, que nació en Zamora en 1777, era amigo de Quintana y había formado parte de las tertulias dirigidas por éste, en dónde conoció a personalidades de la talla de Antonio Alcalá Galiano, Meléndez Valdés, Blanco-White, Antillón, o Sánchez Barbero, entre otros. En la biografía de Gallego destaca que fue decano del Tribunal de la Rota, secretario perpetuo de la Academia de la Lengua, canónigo en Sevilla, vocal del Consejo de Instrucción Pública y Senador del Reino. Tras ser diputado desde 1810 estuvo preso dieciocho meses en 1814, posteriormente fue confinado durante cuatro años a la Cartuja de Jerez y en el convento de Loreto, de donde le sacó la revolución de 1820. Respecto a su actividad literaria hay que destacar sus odas al Dos de Mayo, o a la Defensa de Buenos Aires, que lo han convertido en uno de los primeros líricos de habla española. Murió en Madrid en 1853.
} 
El pensamiento político de Blanco-White...

Las Cortes generales y extraordinarias quieren que el Consejo de Regencia, recogiendo un ejemplar del número 13 del periódico escrito en Londres con el título de El Español, le haga pasar a la Junta territorial de Censura, para que calificándole conforme a los méritos que ofrezca así a este número, como otros del mismo periódico que debe examinar, obren en consecuencia los tribunales respectivos, así respecto al papel como al nombre del autor, con arreglo a las leyes relativas a esta materia (Diario de Sesiones de las Cortes Generales y Extraordinarias, núm. 235, p. 1121).

Esta última proposición es un ejemplo del avance que en materia competencial se esta produciendo a raíz del decreto sobre libertad de imprenta. Se atribuye las funciones que deben desempeñar tanto el Consejo de Regencia, que queda como un simple intermediario que remite el escrito pero que no entra en su calificación y la Junta territorial de Censura, que aparece como una entidad con potestad para calificar el escrito y analizar los ilícitos, y finalmente dar los indicios de delito por las calumnias e injurias que contiene remitiéndolo a los Tribunales para decidir la sanción o medida que se debe imponer.

El cotejo de firmas, la proclamación de la inocencia y su verificación mediante pruebas presentadas a las Cortes son aspectos que destacan a lo largo de los debates. Buen ejemplo de ello es la sesión del día 2 de agosto de 1811, en la que el diputado Pérez señala que el autor del periódico titulado El Español introdujo una carta que reproducía su firma en el número 13 de dicha publicación, y posteriormente en el número 15. Ante una situación falsa, pues según testimonio del diputado Pérez, esa no es su rúbrica, presentó otros documentos de su letra y firma del año 1809 para que pudieran ser cotejados y comprobar la veracidad de su autoría. Con ello pretende limpiar su reputación pero también demostrar la falsa atribución que le hicieron. También solicita una certificación de los Sres. Secretarios de la conformidad o desemejanza de las firmas de las cartas supuestas, y de las que constan en el libro de Actas, pidiendo que se le devuelvan los documentos originales que ha presentado, para salvaguardarse de cualquier imputación que le pudieran hacer. Sin embargo, y pese al agravio que esta publicación bajo firma falsa ha supuesto para el diputado Pérez y el embajador de Portugal, señala que perdona la injuria y que no procederá contra el autor:

En la sesión pública del 24 de Mayo hice presente la impostura y en la sesión de hoy manifiesto las pruebas de lo que entonces dije. Pido a $\mathrm{V}$. M. que se me dé una certificación por los Sres. Secretarios de la conformidad o desemejanza de las firmas de la carta supuesta, y de las que constan en el libro de Actas, y que se me devuelvan originales los documentos que he presentado. La pido, no para valerme de ella contra persona alguna, sino para que me sirva de resguardo en cualquier imputación que pudiera hacérseme a consecuencia de esto, y para los efectos que me convengan. Ya desde el principio supe quién era el autor de esta impostura: luego, más adelante, me confirmé más en ello, y solo siento que se haya comprometido el ministro embajador de Portugal; pero declaro, y protesto solemnemente, que no procederé de manera alguna contra el autor, a quién perdono la injuria (Diario de Sesiones de las Cortes Generales y Extraordinarias, núm. 304, p. 1558).

Desde el punto de vista jurídico esta idea contrasta con la vaguedad e imprecisión en su formulación, pues si realmente se siente ofendido debería iniciar un procedi- 
miento judicial contra todo aquel que ataca el honor de una forma tan violenta como es un escrito bajo firma falsa. Todo ello nos lleva a reflexionar sobre los motivos que este diputado puede tener para decidir no denunciar y decirlo en las Cortes de una forma tan contundente. De hecho hay diputados como Zorraquín ${ }^{9}$ que no entienden cómo puede actuar así cuando el asunto afecta al Congreso y a los americanos. Él piensa, al igual que el diputado Del Pan, que se debería abrir una investigación que aclarase el autor de la carta:

Yo quisiera que se llevase a cabo la averiguación del autor de la carta, porque esto es burlarse ya de V. M., lo que no debe en manera alguna tolerarse (Diario de Sesiones de las Cortes Generales y Extraordinarias, núm. 304, p. 1558).

El Vicepresidente piensa que es correcta la postura del diputado Zorraquín, y añade que dicha búsqueda de la autoría se hará sin perjuicio de la confrontación de firmas y certificación que pide el Sr. Pérez.

Argüelles reflexiona sobre la configuración delictiva de estos actos y se plantea cómo actuar de oficio si el propio afectado no presenta denuncia. Señala que el Sr. Pérez pude tener un inconveniente moral y acaso físico, de manifestar cuál es el autor. $Y$ considera que él es uno de los más interesados en la averiguación y castigo de esta clase de delitos porque podría darse el caso de que en el futuro se viera afectado por un acto similar y que no podrá defenderse de la misma forma que lo hizo el Sr. Pérez. Además, resalta que el Congreso fue insultado, y no puede desatenderse de este asunto arrastrándolo por los sentimientos generosos de un caballero que olvidó la injuria. En el fondo, Argüelles piensa que no es correcta la actitud que está tomando este diputado y reconoce que se debería actuar para evitar que otros diputados fueran injuriados a través de un escrito falso incluido en un periódico. Al hablar de límites físicos, Argüelles muestra un problema real como es la falta de desarrollo de la legislación internacional, y la imposibilidad de hacer reclamaciones en la que los sujetos afectados piden respuesta legal en un Gobierno extranjero. El conflicto entre el sujeto pasivo español que es víctima de la injuria, y la falta de apoyo jurídico del Gobierno inglés, mostraba las deficiencias jurídicas que internacionalmente sufría España en aquel periodo. De hecho, sólo se podía pedir que el gobierno inglés se preocupara por el asunto y tomara acciones, porque el Derecho español no era competente para juzgar y condenar a un autor de ilícito que estaba en el extranjero; o aun siendo competente para enjuiciar los hechos, surgía la duda de cómo aplicar la sanción físicamente, pues territorialmente el autor de los hechos está en el extranjero.

Finalmente las Cortes accedieron a las peticiones del diputado Pérez en todas sus partes. Dejando con ello un cierto vacío a la hora de investigar nuevos caminos jurídicos que intentaran superar los lastres internacionales. La postura de Pérez es decepcionante, se salvaguarda su honor pero es incapaz de intentar ir más allá, gana la batalla moral ante sus compañeros diputados y recupera su honor pero pierde la guerra internacional y deja impune al autor.

\footnotetext{
9 Diputado suplente por Castilla, jurista y miembro del antiguo Consejo de Castilla. Defendió la libertad
} de imprenta. 
El pensamiento político de Blanco-White...

Las presiones que determinados diputados pudieron hacer, ante la decisión del afectado de dejar sin castigo al autor, desencadenaron una serie de cambios al día siguiente en la sesión del 3 de agosto de 1811. Zorraquín pidió que se procediera con arreglo a las leyes al descubrimiento del autor o autores de la carta y firma, y que se dictaran las providencias a las que hubiera lugar. Así era recogida su propuesta en el Diario de Sesiones:

Quizá sin perjuicio de lo pedido por el Sr. Pérez y lo demás que pueda convenirle, no se desentiendan las Cortes el notorio agravio que se les ha hecho con la suplantación de la carta y firma dirigidas al autor del periódico intitulado El Español, en que se toma el nombre del Presidente que era del Congreso, para desacreditar con más apariencia de razón y mayor seguridad sus determinaciones. Que a su consecuencia, y para no dejar impunes semejantes atentados, que pueden ocasionar resultas muy peligrosas, acuerde el Congreso se proceda con arreglo a las leyes, y con la mayor posible energía, al descubrimiento del autor o autores de la enunciada carta y firma, y seguidamente a dictar las demás providencias que haya lugar según el resultado de las diligencias (Diario de Sesiones de las Cortes Generales y Extraordinarias, núm. 305, p. 1811).

Esta postura, que entra dentro de la lógica en un asunto tan grave como el que se estaba planteando fue secundada por otros diputados. Terrero ${ }^{10}$ confirma estas ideas y añade que este delito era de los más atroces, y tan digno de castigo que si su mismo padre lo hubiese cometido, el sería el primero en pedir su exterminio (Diario de Sesiones de las Cortes Generales y Extraordinarias, núm. 305, p. 1561).

La proposición fue aprobada sin posterior discusión, y se empezó a discutir sobre el Tribunal que debería ser competente para estudia e investigar el caso. El diputado Creus propuso que fuera al Tribunal de Cortes, una proposición que se siguió con determinadas matizaciones. Zorraquín apoyó la propuesta, si bien para darle rapidez cambió el sistema de proceder que obligaba al Tribunal a dar conocimiento de todas sus providencias al Consejo de Regencia. Se leyó en público el decreto de creación del Tribunal especificando que se habían variado sus circunstancias. Esta decisión contó con los votos a favor de Gallego, Borrull, Morales Gallego, Villanueva y Obispo de Calahorra, con la única contradicción del Sr. Villagómez.

Al igual que en otros casos de injurias el órgano jurisdiccional competente para conocer de estos asuntos era el Tribunal de Cortes. Sin embargo, podemos observar cómo había un cierto interés porque un órgano político como el Consejo de Regencia tuviera conocimiento de los asuntos jurídicos, especialmente aquéllos en los que se produjeran atentados contra la libertad de imprenta. Su necesidad de tener conocimiento de estos asuntos entorpecía en algunos momentos la labor del propio Tribunal de Cortes como implícitamente reconoce Zorraquín. Por ello, proponen darle agilidad evitando trámites procesales que entorpecerían el asunto.

\footnotetext{
10 Diputado por Cádiz. Era cura por Algeciras, y de difícil calificación entre liberal o servil. Su estilo era enfático, con expresiones populares y maliciosas. En los inicios del Congreso defendió la causa de los guerrilleros contra el ejército, sin embargo, se advierten una serie de contradicciones en sus ideas. Así se manifestó a favor de la idea de soberanía popular pero también asumía la intolerancia religiosa representada por la Inquisición. Sus postulados defendían al Trono y el Altar, una indeterminación en algunos postulados de su discurso que le valió ser objeto de burlas.
} 
El 8 de agosto de 1811 se encargó al Tribunal de Cortes practicar las diligencias necesarias para descubrir al autor o autores de la carta dirigida al editor del periódico de El Español bajo la firma del diputado Antonio Joaquín Pérez. Las Cortes concedieron permiso al diputado afectado para que pudiera informar sobre cuanto le fuera preguntado por el Tribunal para resolver el asunto.

Los Diarios de Sesiones encierran un cierto vacío a la hora de enfocar los asuntos judiciales, pues no se recoge el fallo y decisiones jurídicas que se aportaron, si es que finalmente se pudo llegar a una solución, pues, como hemos destacado, las dificultades competenciales en el ámbito internacional se multiplican, y el derecho del momento es insuficiente para paliar la variada casuística que se está planteando. De hecho, hemos comprobado cómo en territorio nacional no podían controlarse correctamente muchos de los abusos que los impresores cometían; más difícil es intentar solventar un conflicto con una víctima española, un presunto autor inglés y una publicación como El Español que trasciende las fronteras nacionales. No obstante, hay que alabar la labor que desde las Cortes se está haciendo por intentar resolver los asuntos a pesar de las limitaciones con las que cuentan. La postura de los diputados, firme, decidida y, sobre todo justa, es un síntoma de que las estructuras políticas estaban implicándose en la búsqueda de soluciones ante los ataques que se cometían a través de la prensa. En base a estas circunstancias se quiere perseguir al autor de los hechos para exigirle responsabilidad por sus actos. Los canales internacionales están empezando a funcionar, se esta viendo la necesidad de crear las estructuras jurídicas internacionales necesarias que sirvan para juzgar casos como el presente. La diplomacia en el tratamiento de estos asuntos, donde los Gobiernos español e inglés se veían involucrados, hacía necesaria una actuación muy prudente, de ahí que las Cortes intervengan cuidando el mayor número de formalidades que se exige en estos procesos. Todos estos debates, reflexiones y posturas servirán para nutrir las legislaciones y crear precedentes jurisprudenciales, pero no hay que olvidar que si no hubiera sido por la implicación de los diputados de Cortes, muchos de estos asuntos que estamos conociendo gracias a los Diarios de Sesiones, fiel testimonio de lo que pasó, quedarían en el olvido.

\section{LA DESAPARICIÓN DE EL ESPAÑOL Y EL DESARROLLO DE LA PRENSA EN EL EXILIO}

El Español desde su origen fue perseguido, y como hemos ido comentando a lo largo de este estudio, se buscaron diversas formas para evitar la entrada de esta publicación a la península. De hecho, la Regencia prohibió bajo penas graves y según decreto de 15 de noviembre de 1810, la introducción de los números de dicho periódico. Se señala a Blanco como un proscrito reo de la nación, al tiempo que se le definía de eterno adulador de D. Manuel Godoy. En la última publicación de El Español, número de mayo-junio de 1814, aparece un trabajo titulado "Conclusión de esta obra" en la que relata que ha estado cuatro años trabajando duramente para sacar este periódico, superando obstáculos como la injusticia, el insulto o el abandono de amigos declarados muchos de ellos enemigos. Considera que la democracia de las Cortes había sido mal fraguada y pensó que un cambio político podría ser beneficioso. Califica a las Juntas de Censura como inquisiciones filosóficas comparables en su intolerancia al Santo Oficio. Blanco reconoce que España sólo se podrá poner al nivel que el resto de naciones europeas si estableciera un gobierno fundado en los principios que han elevado a Inglaterra al puesto en que se halla, como 
El pensamiento político de Blanco-White...

la libertad religiosa y civil (Tobajas, 1984: 179-181). Sus palabras finales son toda una reflexión sobre el papel que ha jugado España en los últimos años. Las Cortes, en su opinión, han traicionado el ideal liberal que las inspiraron para ser otro mecanismo de control político, otra expresión o manifestación de poder, que crea sus propios instrumentos de ejecución como las Juntas de Censura.

La llegada de Fernando VII hizo que Blanco albergara esperanzas de renovación entre los sectores liberales y serviles, marcados por un tono extremado en sus convicciones, en que se había dividido España. Sin embargo, se equivocó como lo demuestra el decreto de 4 de mayo de 1814 que fue publicado en el último número de El Español. El decreto de Valencia de 4 de mayo de 1814 señala el reconocimiento expreso de Fernando VII de no jurar ni acceder a la Constitución de 1812, ni a los decretos de las Cortes Generales y Extraordinarias ni de las Ordinarias actualmente abiertas, considerándolos como nulos, y de ningún valor ni efecto (Flaquer Montequi, 1991: 64-65). Todo el trabajo de las Cortes es tirado abajo en un desplante de autoridad, absolutismo y prepotencia del monarca Fernando VII a su Ilegada. Las críticas a las Cortes que Blanco había realizado tenían como objeto mejorar la situación política de España; de hecho pensaba que el monarca iba a mantener el sistema de las Cortes limando sólo los defectos que encontrara en el sistema, pero lo que realmente ocurre es una ruptura total con las Cortes y una vuelta al despotismo del Antiguo Régimen.

Los artículos de El Español que estuvieron saliendo en el periodo de vida de la publicación fueron obra del propio Blanco-White y van firmados con las iniciales que adoptó en Inglaterra "B. W." También firmó con el seudónimo de Juan Sin Tierra, que adopta especialmente a partir del número 12 para artículos escritos con un tono más desenfadado propio de la evolución de sus ideas hacia un carácter más moderado o para contestar a los amigos que lo traicionaban. Sin embargo, es justo mencionar la participación en la publicación de autores como Flórez Estrada o Martínez de la Rosa. Como hemos observado a lo largo del caso analizado de los Diarios de Sesiones de las Cortes de Cádiz, se menciona por parte de los diputados la referencia al nombre Juan Sin Tierra. Este seudónimo, que ocultaba al editor Blanco-White, sirvió para dar un tono hiriente pero dotado de un carácter sarcástico y en algún momento humorístico a determinados escritos. Blanco-White vio como sus amigos diputados le descalificaban en público, e incluso le atacaban en las sesiones de las Cortes. La humillación y el escarnio a que fue sometida su persona y el periódico que editaba, tuvieron como resultado una contrarréplica a través de artículos de opinión que criticaban las decisiones políticas de las Cortes. Había, según Blanco, una mal entendida idea del liberalismo y eso era conveniente ponerlo de manifiesto, aunque para ello utilizara sobrenombres que reflejaban el sentir de un hombre que había dejado su patria.

Las campañas políticas de El Español de 1810 a 1814 lo enfrentaron de tal manera con los liberales de Cádiz, que prácticamente fue imposible su reconciliación. Para la mayoría de los refugiados en Londres, Blanco seguiría siendo Juan Sin Tierra (Lloréns, 1979: 411).

Blanco-White recibió del Gobierno inglés una pensión vitalicia por los servicios que había prestado en el tiempo que trabajó informando a los ciudadanos. El propio Blanco explica que El Español había tenido una gran influencia en el público espa- 
ñol, y que el embajador británico de Cádiz, Sir Henry Wellesley, que se había visto asediado por la gente pidiéndole ejemplares de dicha publicación, había hecho una recomendación al Ministerio de Asuntos Extranjeros (que en ocasiones encargó la realización de traducciones a Blanco) para que le dieran una pensión anual de ciento veinticinco libras. Además, reconoce que sabía que el gobierno inglés estaba muy bien informado sobre los buenos efectos que El Español estaba generando en la opinión pública para combatir las críticas antibritánicas (Tobajas, 1984: 182-183). El Español había apoyado los intereses ingleses y fue un instrumento difusor de gran relevancia en España, algo que no pasó desapercibido a cargos como el embajador británico, que era consciente del impacto social que estaba gestándose. Hay que reconocer el mérito de Blanco-White de sacar un periódico en Inglaterra que analizaba y cuestionaba las acciones políticas de España, superando obstáculos y con las dificultades que esto debía suponer. El Español fue un periódico que nace desde el rencor de un liberal que siente dolor al ver como su país es víctima de la demagogia institucional. Este periódico fue un baluarte de muchos intelectuales que entendían que se debían hacer posicionamientos que superaran los controles que sufría España a través de las Juntas de Censura, y que cuestionaran con realidad los temas que preocupaban a la sociedad.

No sería justo terminar este estudio sin resaltar que la figura de Blanco-White fue, desgraciadamente, incomprendida por los políticos y la sociedad de su tiempo. Se le tachó de afrancesado o anglófilo sin entender que detrás de esa imagen superflua se encerraba un español universal abanderado de la idea de libertad. No fue traidor a los intereses de su patria porque era un liberal con un españolismo más amplio que el de sus propios acusadores de Cádiz. Una visión del liberalismo tan universal que atravesaba el Atlántico, para buscar el hermanamiento entre españoles y americanos (Seco Serrano, 1983: 275). Por eso se hace necesario reseñar que este autor fue un adelantado en su tiempo. Tuvo una visión del liberalismo que traspasaba fronteras, y que, desgraciadamente, no fue entendida en una España abierta al cambio, pero todavía anclada en valores tradicionales que hacían muy difícil esa transición.

El Español abrió la brecha para el desarrollo de otra prensa liberal en el exilio. A la suspensión de El Español siguió la aparición de otros títulos hispano-londinenses, entre los que destaca El Español Constitucional (1816-1820), del exaltado Fernández Sardino. La mayor parte de los periódicos editados por españoles en Inglaterra lo fueron durante el segundo exilio, después de la subida de nuevo al trono de Fernando VII como rey absoluto en 1823. En los siguientes siete años Londres se convirtió en la capital intelectual de la España libre, hasta que la revolución de julio de 1830 en Francia permite el traslado de la mayor parte de los emigrados a París. En Francia encontraremos referentes importantes de españoles como el Conde de Toreno, Martínez de la Rosa, J .A. Yandiola, Joaquín María Ferres y Andrés Borrego. Blanco-White fue el precursor de un grupo de luchadores que, desde otros países y con la añoranza que sienten hacia su tierra natal, se implicaron en publicaciones que analizaban las noticias y cuestiones políticas de España.

\section{CONCLUSIONES}

Una vez analizados los debates de las Cortes de Cádiz respecto al número 13 del periódico El Español podemos señalar, a modo de conclusión, que la prensa en el exilio tuvo gran influencia en el público de España. El exponente crítico que los pe- 
El pensamiento político de Blanco-White...

riódicos, realizados en el extranjero, tenían respecto a los asuntos peninsulares, como es el caso de El Español, suscitó el interés de la sociedad. Las publicaciones de los exiliados atacaron y desacreditaron las instituciones españolas, lo que determinó una reacción adversa por parte de los políticos de las Cortes de Cádiz que hicieron todo lo posible por frenar la distribución de dichos periódicos.

El tono exaltado de la prensa en el exilio generó la necesidad de estudiar los límites jurídicos de la libertad de imprenta. Casos como el suscitado en el número 13 del periódico El Español, en el que un diputado siente su honor mancillado por una publicación, determinó que las Cortes de Cádiz empezaran a debatir sobre la responsabilidad de los editores e impresores en los contenidos que publicaban, especialmente cuando se vulneraban derechos fundamentales. La proliferación de estas situaciones implicó un endurecimiento de las penas y sanciones para este tipo de ilícitos, que contrasta con ese liberalismo utópico que los diputados de las Cortes de Cádiz querían infundir en los primeros textos legales sobre libertad de imprenta. Además, hay que señalar que la publicación en el exilio de noticias que atentaban contra el honor de los políticos españoles, generaba también un conflicto competencial entre diversos Estados Internacionales. El tratamiento jurídico de las publicaciones de los exiliados cuando se injuria o ataca a políticos e instituciones de España, conlleva una confusión sobre cuál sería en estos casos el Tribunal competente que debería investigar y juzgar estos asuntos. Los diplomáticos españoles se ponen en contacto con el Gobierno inglés, en los ataques promovidos por el periódico El Español, para buscar una solución a estas cuestiones. No obstante, observamos que no hay elementos legales suficientes que diriman estos conflictos competenciales. Por tanto, el desarrollo de la prensa en el exilio evidenció la carencia de instrumentos jurídicos internacionales de resolución de conflictos, y la necesidad de desarrollar textos legales que solventarán estas situaciones.

El importante desarrollo de la libertad de imprenta que se produjo en el periodo de 1810 a 1813, hizo muy difícil controlar con rigurosidad todas las publicaciones que salían. A eso hay que unir la labor de periódicos que se imprimían en el extranjero pero llegaban y se distribuían en España. Esta prensa en el exilio gozaba de un grado de impunidad aun mayor que las propias del territorio español. Conflictos competenciales de jurisdicción, junto con las limitaciones geográficas, hicieron muy difícil controlar a estos periódicos y evitar su publicación.

Sin embargo, hay que destacar que el desarrollo de la prensa en el exilio supuso un nuevo concepto del contenido informativo. El periódico El Español, fue un referente para la prensa de años posteriores, su estilo claro, preciso y cargado de implicación por parte de su editor, sirvió para que otros intelectuales sacaran publicaciones similares. En el fondo todos buscaban informar y educar a la sociedad dentro de un complejo marco político internacional. Quizás esa es la herencia que nos dejó Blanco-White, símbolo de la constante lucha por un ideal; su ejemplo, la capacidad de superar obstáculos y la creencia del hombre en sus proyectos, a pesar de las dificultades de la vida, es un legado inmortal que ha servido para inspirar a generaciones de periodistas e intelectuales, y que todavía hoy, en los días presentes, debemos valorar. 


\section{REFERENCIAS BIBLIOGRÁFICAS}

BLANCO-WHITE, J. M. Autobiografía de Blanco-White. Edición, traducción y notas de Antonio Garnica. Sevilla: Servicios de Publicaciones de la Universidad de SeviIla, 1988.

- (1973) Cartas de España. Edición y traducción de Antonio Garnica. Madrid: Alianza Editorial, 1973.

DIARIO DE SESIONES DE LAS CORTES GENERALES Y ESTRAORDINARIAS, núm. 235 (24 de mayo de 1811); núm. 304 (2 de agosto de 1811); núm. 305 (3 de agosto de 1811); núm. 310 (8 de agosto de 1811).

FLAQUER MONTEQUI, R. El ejecutivo en la Revolución liberal. En VV. AA. Las Cortes de Cádiz. Madrid: Marcial Pons, 1991, pp. 37-65.

GOYTISOLO, J. Obra inglesa de Blanco-White. Madrid: Alfaguara, 1999.

LLORÉNS, V. El romanticismo español. Madrid: Editorial Castalia, 1989.

- (1979) Liberales y románticos. Una emigración española en Inglaterra (1823-1834). Madrid: Castalia.

MORENO ALONSO, M. Blanco White. La obsesión de España. Sevilla: Ediciones Alfar, 1998.

RAMOS SANTANA, A. La Ilusión Constitucional: Pueblo, patria, nación. De la llustración al Romanticismo. Cádiz, América y Europa ante la Modernidad. 1750-1850. Cádiz: Servicio de Publicaciones de la Universidad de Cádiz, 2004.

SÁNCHEZ GARCÍA, R. Interpretaciones del Trienio Liberal: aciertos y errores del liberalismo. En RAMOS SANTANA, A. La Ilusión Constitucional: Pueblo, patria, nación. De la llustración al Romanticismo. Cádiz, América y Europa ante la Modernidad. 1750-1850. Cádiz: Servicio de Publicaciones de la Universidad de Cádiz, 2004, pp. 225-234.

SECO SERRANO, C. Blanco White y el concepto de 'revolución atlántica'. En VV.AA. La prensa en la Revolución liberal. España, Portugal y América Latina. Madrid: Universidad Complutense, 1983, pp. 265-275.

TOBAJAS, M. Periodismo Español. Notas para su historia. Madrid: Forja, 1984.

VALLS, J. F. Prensa y burguesía en el XIX español. Barcelona: Anthropos, 1988.

VARELA SUANZES, J. "Un precursor de la monarquía parlamentaria: Blanco-White y El Español (1810-1814)”. Revista de Estudios Políticos, 1993, n²79, pp. 101-120.

VV. AA. Las Cortes de Cádiz. Madrid: Marcial Pons, 1991. 
El pensamiento político de Blanco-White...

\section{Breve semblanza del autor}

Jesús López de Lerma Galán es Doctor en Historia del Periodismo y Derecho a la Información por la Universidad de Sevilla. También tiene las Licenciaturas de Derecho y Periodismo, y ha sido Becario del Congreso de los Diputados de Madrid. Su ejercicio profesional se ha desarrollado en diversos medios de comunicación como Onda Cero, Canal Sur y Cadena Ser, entre otros. En la actualidad compatibiliza su actividad académica con su trabajo como abogado y director de comunicación.

(Recibido el 28-11-07, aceptado el 3-01-08) 